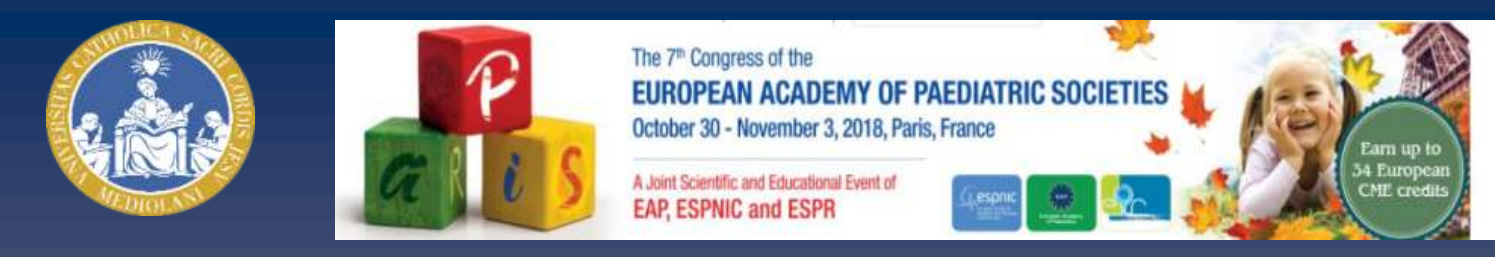

\title{
Pediatric aPL related motor neuropathy and IVIG
}

\author{
Brogna $C^{1}$, Luiggetti $\mathbf{M}^{2}$, Norcia $\mathbf{G}^{3}$, Scalise $\mathbf{R}^{1}$, Ferrantini $\mathbf{G}^{3}$, Mercuri $\mathrm{E}^{1}$, Pane $\mathbf{M}^{3}$ \\ ${ }^{1}$ Pediatric Neurology Unit, «Sacro Cuore» Catholic University, Rome Italy \\ ${ }^{2}$ Neurology Unit , Fondazione Policlinico Gemelli, Rome, Italy \\ ${ }_{3}^{3}$ Pediatric Neurology Unit, Fondazione Policlinico Gemelli, and Nemo Center, UCSC Rome, Italy.
}

\section{INTRODUCTION}

In the last years there are an increased number of children affected by underlying autoimmune diseases associated with neurological manifestations, as the first clinical sign. In most cases the timing and the type of immunomodulant therapy is important to consider to have a successfully outcome.

We report a paediatric clinical case characterized by the onset of acute motor polyneuropathy in presence of persistent LAC positivity successfully treated with IVIG.

\section{CASE}

A healthy, nine-year-old girl progressively presented with gait disturbance, frequent falls, difficulty in jumping and rising from the ground. Neurological examination showed mild muscular weakness and absent tendon reflexes at the lower limbs, incomplete Gowers sign, difficulty walking on heels, jumping and instable static and dynamic balance.

\section{METHODS AND RESULTS}

\begin{tabular}{|c|c|c|}
\hline \multicolumn{3}{|c|}{ Laboratory assessment } \\
\hline Autoimmunity & $\begin{array}{l}\text { ASMA, AMA, ENA, ANA, anti Nucleosome, } \\
\text { anti Centromere, anti Jo1, p ANCA/c ANCA, } \\
\text { anti sDNA, anti GAD, anti SCL 70, anti } \\
\text { Citrulline, Anti endomysial and anti } \\
\text { transglutaminase, Antigangloside and } \\
\text { aquoporin antibodies, Cryoglobulins, } \\
\text { Immune Complexes, C3, C4 }\end{array}$ & $\mathrm{Neg}$ \\
\hline aPL & $\begin{array}{l}\text { Lupus anticoagulant, Anti } \beta 2 \text { glycoprotein } \\
\text { antibodies, } \\
\text { Anticardiolipin antibodies } \\
\text { Antiprothrombin antibodies }\end{array}$ & $\begin{array}{l}\text { LAC + } \\
\text { drVV } \\
\text { ratio + }\end{array}$ \\
\hline $\begin{array}{l}\text { Onco-neural } \\
\text { Antibodies }\end{array}$ & $\begin{array}{l}\text { Anti Yo, Anti Ri, Anti Hu, anti CCU2, Anti } \\
\text { AGNA, anti Me }\end{array}$ & $\mathrm{Neg}$ \\
\hline Serum exams & $\begin{array}{l}\text { Erytrocyte sedimentation rate, C-reactive } \\
\text { protein, ASO titer, Ammonium, Serum } \\
\text { lactate, Serum ceruloplasmin } \\
\text { Copper serum and urine levels, rheumatoid } \\
\text { factor, Serum free thyroid hormones, CPK, } \\
\text { Cromogranina A, neuron specific enolase, } \\
\text { CEA }\end{array}$ & $\mathrm{Neg}$ \\
\hline $\begin{array}{l}\text { Anti-neuron } \\
\text { antibodies }\end{array}$ & $\begin{array}{l}\text { anti NMDAR, anti GABA b, anti Lgi-1, Anti } \\
\text { CASPR } 2\end{array}$ & $\mathrm{Neg}$ \\
\hline Sierology & $\begin{array}{l}\text { Herpes, Cytomegalovirus, Enterovirus, } \\
\text { Parvovirus, Epstein Barr virus, mycoplasma, } \\
\text { TORCH, varicella, measles, adenovirus, } \\
\text { mumps, echovirus, influenza A and B, } \\
\text { Coxsackie, Borrelia burgdorferi, Parvovirus } \\
\text { B19 IgM and IgG }\end{array}$ & $\mathrm{Neg}$ \\
\hline $\begin{array}{l}\text { Hereditary clottin } \\
\text { exams }\end{array}$ & $\begin{array}{l}\text { antithrombin, protein } \mathrm{C} \text { and protein } \mathrm{S} \text {, factor } \\
\mathrm{V} \text { Leiden, prothrombin } 20210 \mathrm{~A} \text { gene } \\
\text { mutation, polymorphism of } \\
\text { methylentetrahydrofolate reductase }\end{array}$ & $\mathrm{Neg}$ \\
\hline
\end{tabular}

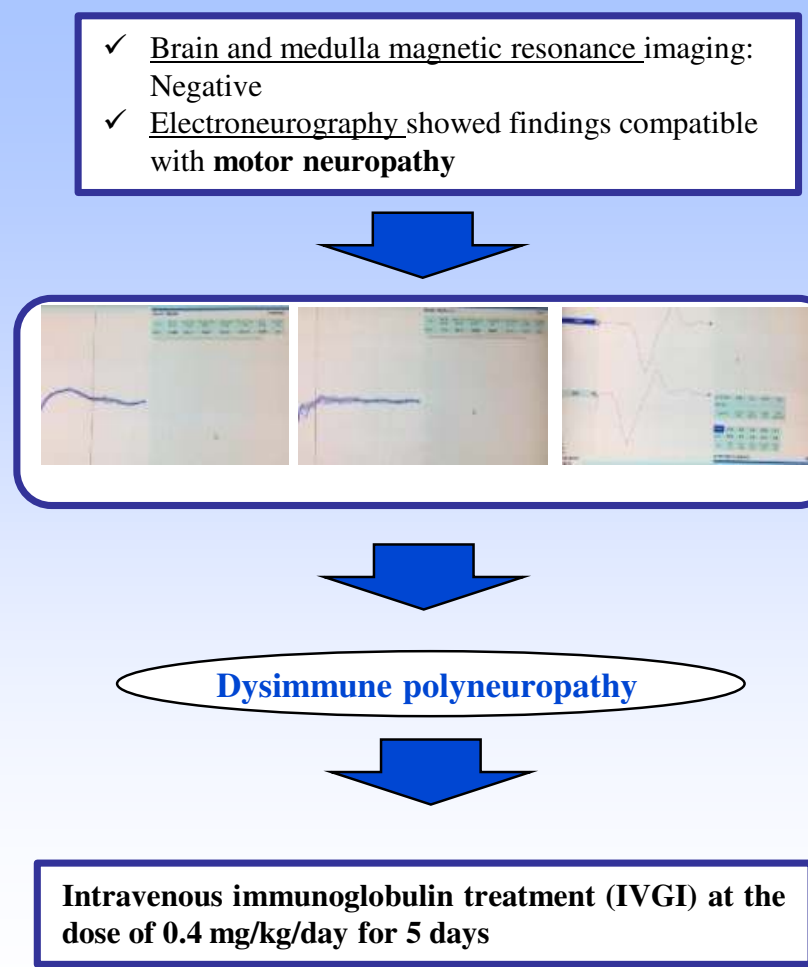

\section{Rapid improvement after IVIG}

\begin{tabular}{|c|c|c|c|c|}
\hline \multirow[b]{2}{*}{$\begin{array}{l}\text { IVIG } \\
\text { treatment }\end{array}$} & \multirow{2}{*}{$\begin{array}{l}\text { Hammersmith } \\
\text { Functional } \\
\text { Motor Scale } \\
\text { (HFMS) }\end{array}$} & \multicolumn{2}{|c|}{ North Star } & \multirow[b]{2}{*}{ 6MWT } \\
\hline & & $10 \mathrm{mt}$ & $\begin{array}{l}\text { Rise } \\
\text { from } \\
\text { floor }\end{array}$ & \\
\hline Before IVIG & $\begin{array}{l}56 / 66 \text { (squat } \\
\text { difficulty) }\end{array}$ & $8,70 \mathrm{sec}$ & $\begin{array}{l}9.38 \mathrm{sec} \\
\text { (Incomple } \\
\text { te } \\
\text { Gowers) }\end{array}$ & $323 \mathrm{mt}$ \\
\hline $\begin{array}{l}1 \text { Month } \\
\text { after IVIG }\end{array}$ & $\begin{array}{l}\text { 64/66 (mild diff } \\
\text { squat) }\end{array}$ & $\begin{array}{l}5.65 \mathrm{sec} \\
\text { No } \\
\text { double } \\
\text { stance }\end{array}$ & $\begin{array}{l}2.21 \mathrm{sec} \\
\text { (High } \\
\text { kneeling) }\end{array}$ & $489 \mathrm{mt}$ \\
\hline $\begin{array}{l}2 \text { months } \\
\text { after IVIG }\end{array}$ & $\begin{array}{l}65 / 66 \\
\text { (incomplete } \\
\text { squat) }\end{array}$ & $\begin{array}{l}5.52 \mathrm{sec} \\
\text { with } \\
\text { double } \\
\text { stance }\end{array}$ & $\begin{array}{l}5.52 \mathrm{sec} \\
\text { (High } \\
\text { kneeling) }\end{array}$ & $517 \mathrm{mt}$ \\
\hline $\begin{array}{l}4 \text { months } \\
\text { after IVIG }\end{array}$ & $\begin{array}{l}66 / 66 \text { (complete } \\
\text { squat) }\end{array}$ & $\begin{array}{l}3.23 \mathrm{sec} \\
\text { with } \\
\text { double } \\
\text { stance }\end{array}$ & $\begin{array}{l}2.48 \mathrm{sec} \\
\text { (High } \\
\text { kneeling) }\end{array}$ & $571 \mathrm{mt}$ \\
\hline
\end{tabular}

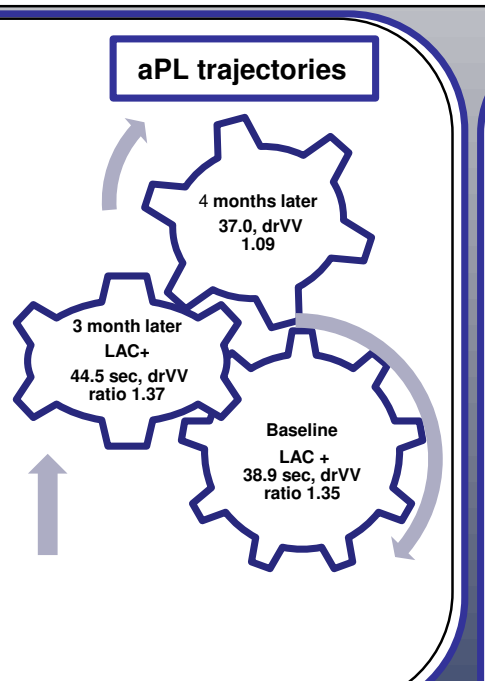

\section{References:}

Brogna et al Conventional and intravenous immunoglobulin therapy in paediatric antiphospholipid antibodies-related chorea, Lupus 2014;

- Katzav A et al CNS dysfunction in the antiphospholipid syndrome. Lupus 2003; 12: 903-907 - Giannakopoulos B, Krilis SA. N Engl J Med. 2013

\section{CONCLUSIONS}

This young girl developed a motor polyneuropathy in presence of persistent LAC positivity resembling a non-thrombotic clinical manifestation aPL related that are common in pediatric population. Our findings suggest the importance:

$\checkmark$ To consider apL antibodies as a Reading key underpinning a more specific dysimmune mechanism.

$\checkmark$ To check aPL in children with a rapid onset of neurological signs in order to provide the beneficial use of IVGI in the treatment of pediatric aPL neurological conditions. 